\title{
Nutritional intervention in childhood overweight - Efficacy of the motivational multidisciplinary individualized treatment
}

\author{
Vânia Cabral ( $\sim$ vmargaridacabral@hotmail.com ) \\ Universidade de Lisboa Faculdade de Medicina \\ Inês Asseiceira \\ Universidade de Lisboa Faculdade de Medicina \\ Joana Sousa \\ Universidade de Lisboa Faculdade de Medicina
}

Research article

Keywords: Childhood overweight, nutritional intervention, behavioral contract

Posted Date: July 10th, 2020

DOl: https://doi.org/10.21203/rs.3.rs-40782/v1

License: (c) (1) This work is licensed under a Creative Commons Attribution 4.0 International License. Read Full License 


\section{Abstract}

Background: The increase in prevalence of pre-obesity and childhood obesity in most European countries led to the need to develop effective interventions to reverse this situation. The aim of this study was to evaluate the efficacy of a behavioral protocol for the treatment of pediatric overweight.

Methods: The study sample consisted of overweight children/adolescents between six and eighteen years old. The individuals who were intervened with the application of a behavioral contract belonged to Behavioral Group (BG) and those who received standard treatment belonged to the Standard Treatment Group (STG). The evolution of the Body Mass Index (BMI) z-score and body composition were evaluated.

Results: The BG significantly decreased the Body Mass Index (BMI) z-score both in the middle and at the end of the intervention, but the STG only significantly decreased the BMI z-score at the end of the intervention. We were also found that the BG significantly decreased the fat mass index $(p<0,05)$ compared to the STG $(p>0,05)$ after twelve months.

Conclusion: The use of a behavioral approach for the treatment of pediatric overweight showed an improvement in fat mass index and a decrease in BMI at twelve months when compared to a standard intervention. Thus, the behavioral approach seems to be more effective than a standard long-term nutritional approach . In summary, the child's accountability in its overweight treatment process seems to be effective.

\section{Introduction}

Pediatric obesity is considered one of the greatest health challenges of the 21st century[1]. Its negative impact on health ranges from its association with several comorbidities in childhood [2-4], to premature death in adulthood [2].

The treatment of childhood obesity is complex and can might include strategies such as clinical counseling provided to children, structured multidisciplinary programs and surgical intervention [5].

Several interventions have been developed in order to improve the relationship between patients and health professionals, which can indirectly increase adherence to treatment. These interventions highlight the behavioral contract between the patient and the health professional, which consists of a verbal or written agreement in which one or both parties agree with a change of behaviors related to the patient [6]. In the clinical context, behavioral contracts have been used for eating behaviors [6-8], but also smoking cessation, rheumatic diseases, tuberculosis [6] and for individuals with specific psychiatric conditions [9]. A recent systematic review showed efficacy of behavioral contracts in short-term weight gain for the treatment of anorexia nervosa. The authors concluded that use of contracts increases patient participation, responsibility and motivation in their treatment process, emphasizing that there is little evidence on the efficacy of type of intervention in clinical practice [7]. Several authors have shown the effectiveness of contracts to change behaviors with monetary reward in reducing weight in overweight or 
obese adults [10-12]. However, studies using the behavioral contract method for the treatment of overweight in children and adolescents, are scarce. It has been concluded that behavioral interventions result in a clinically significant reduction in overweight in children and adolescents when compared to standard treatment interventions [13].

The failure of a weight loss program is due to the lack of adherence and interest in the program [14]. The use of behavioral contracts has been reported as a behavioral strategy to improve patient compliance with treatment [6].

This study raises the hypothesis that a behavioral approach to nutritional intervention will be more effective than a standard long-term approach and the main objective was to evaluate the effectiveness of applying a behavioral protocol for the treatment of pediatric overweight.

\section{Materials And Methods}

This is a retrospective data analysis study of two groups that received different treatments.

The study population consisted of children and adolescents between six and eighteen years old, of both sexes, who were referred for treatment of overweight and followed at the largest central hospital in Portugal between 2012 and 2017. Children/adolescents with overweight were proposed to nutrition counseling of their multidisciplinary treatment team. The dietitian followed the consultation protocol of his multidisciplinary team. The intervention group protocol included the use of the behavioral contract and time between consultations adjusted to the results of children/adolescents. The control intervention protocol included standard follow-up.

Figure 1 systematizes the course of the interventions under study. In the first visit (M0), a behavioral contract methodology was applied in the BG. This methodology consisted of signing a behavioral contract negotiated between the dietitian, tutors and the children/adolescent, in order to correct the main previously identified food errors (e.g.: skip breakfast, don't eat vegetables, drink soft drinks) through a 24hour recall. A non-material reward was also defined (e.g.: a bike ride, a visit to a theme park, going to a swimming pool) that would be offered by the tutors of the child/adolescent, if they obtained good results (meet at least two-thirds of the objectives set). In the second visit, after 1 month (M1), if the children/adolescent had loss weight, the reward was offered and the nutritional plan was prescribed. Throughout this treatment, the interval between patient visits ranged between monthly and quarterly in the first six months (M2) and between quarterly and half-yearly in the last six months (M3). In the STG, the nutritional plan was prescribed during the first visit (M0) and the time between visits had a higher interval, quarterly in the first six months (M2) and half-yearly in the last six months (M3) relative to the BG.

In both interventions, dietitians also encouraged the practice of physical activity. 
For sample selection, we used the child growth curves of the World Health Organization, which adjust the children's weight, height and Body Mass Index (BMI) according to sex and age [15]. We included only children and adolescents, with BMI z-score $>1$ at the time of admission to the consultation and with at least 12 months follow-up. Children and adolescents with previously diagnosed psychiatric pathology (e.g. autism) or other that compromise the adherence to the program or the collection of the parameters under study were excluded.

The initial sample consisted of 79 children/adolescents of the Behavioral Group (BG) and 153 of the Standard Treatment Group (STG). However, for the analysis of results, only children/adolescents who had at least three assessments (baseline, between three and six months and after 12 months) in the 12months interval were admitted. Thus, according to these criteria, 35 individuals of the BG and 55 of the STG were selected. Figure 2 summarizes the sample selection.

The analyzed data were based on the evolution of the BMI z-score and body composition. All consultations were in-person. In each consultation data was collected for height (measured with stadiometer), weight and body composition, measured by weight scale and bioimpedance equipment with cross-calibration, respectively. Data from the M0 (baseline), M1 (one month after), M2 (six months after) and M3 (12 months after) of follow-up were collected.

Body composition (fat mass, fat mass index, fat free mass and fat free mass index) was interpreted through reference values adjusted for sex and age published by Wells, JC. et al. [16]. Since the fat mass index and the fat free mass index relate fat mass and fat free mass, respectively, with height [17], these two indexes were chosen as preferential to analyze body composition.

All ethical requirements were ensured, and the study was analyzed and approved by the Ethics Committee of the Faculty of Medicine of the University of Lisbon and the North Lisbon University Hospital Center (reference of approval code: 459/18). The informed consent was also approved by the tutors.

Statistical analysis of the data was performed using the Statistical Package for the Social Sciences (SPSS) version 22 (Microsoft Windows $\left.{ }^{\circledR}\right)$.

Descriptive statistics consisted in the calculation of means and standard deviations (SDs) for continuous variables and in the presentation of relative and absolute frequencies for ordinal and nominal variables.

To calculate the differences between groups, we used the Student T test (for independent samples) and the Mann-Whitney test. We also used the Student T test for paired samples or the Wilcoxon test to compare the mean differences between the beginning and the end of the intervention.

For the study of evolution over time by groups, the ANOVA test of repeated measurements and the Friedman test were used. For the comparison between groups in the qualitative variables, the Chi-Square test, Fisher's exact test or the Chi-Square test by Monte Carlo simulation were used. Statistical significance for $p<0,05$ was accepted in all analyzes. 


\section{Results}

\subsection{Sample characterization}

A total of 90 patients were included in the study. The characteristics of the patients and their nutritional status are shown in Table 1. There was no statistically significant difference between the two groups, regarding the mean age, gender, BMI $z$-score, fat mass index and fat free mass index $(p>0,05)$.

Through the analysis of the fat free mass index percentiles [16], in both groups, all children/adolescents had a fat free mass index deficit. 
Table 1

Characteristics and nutritional status at baseline.

\begin{tabular}{|c|c|c|c|c|c|}
\hline & \multicolumn{2}{|c|}{$\begin{array}{l}\text { Behavioral Group } \\
\mathrm{n}=35\end{array}$} & \multicolumn{2}{|c|}{$\begin{array}{l}\text { Standard Treatment Group } \\
\mathrm{n}=55\end{array}$} & p-value* \\
\hline \multirow[t]{2}{*}{ Variable } & \multicolumn{2}{|c|}{ Mean \pm SD } & \multicolumn{2}{|c|}{ Mean \pm SD } & \\
\hline & \multicolumn{2}{|l|}{$\%(n)$} & \multicolumn{2}{|l|}{$\%(n)$} & \\
\hline Age(years) & \multicolumn{2}{|c|}{$11,05 \pm 3,18$} & \multicolumn{2}{|c|}{$12,20 \pm 2,03$} & $0,100^{\mathrm{a}}$ \\
\hline \multicolumn{6}{|l|}{ Gender } \\
\hline Female & \multicolumn{2}{|c|}{$65,7 \%(23)$} & \multicolumn{2}{|c|}{$60 \%(33)$} & $0,586^{\mathrm{b}}$ \\
\hline Male & \multicolumn{2}{|c|}{$34,3 \%(12)$} & \multicolumn{2}{|c|}{$40 \%(22)$} & \\
\hline Weight (kg) & \multicolumn{2}{|c|}{$55,60 \pm 19,38$} & \multicolumn{2}{|c|}{$68,14 \pm 17,86$} & $0,002^{c}$ \\
\hline Height (m) & \multicolumn{2}{|c|}{$1,44 \pm 0,16$} & \multicolumn{2}{|c|}{$1,54 \pm 0,12$} & $0,002^{\mathrm{a}}$ \\
\hline BMI $\left(\mathrm{kg} / \mathrm{m}^{2}\right)$ & \multicolumn{2}{|c|}{$25,96 \pm 4,27$} & \multicolumn{2}{|c|}{$28,13 \pm 3,97$} & $0,016^{c}$ \\
\hline BMI z-score & \multicolumn{2}{|c|}{$2,54 \pm 0,80$} & \multicolumn{2}{|c|}{$2,57 \pm 0,56$} & $0,802^{c}$ \\
\hline \multicolumn{6}{|l|}{ BMI z-score classes } \\
\hline Obesity & \multicolumn{2}{|c|}{$80 \%(28)$} & \multicolumn{2}{|c|}{$83,6 \%(46)$} & $0,660^{b}$ \\
\hline Pre-obesity & \multicolumn{2}{|c|}{$20 \%(7)$} & \multicolumn{2}{|c|}{$16,4 \%(9)$} & \\
\hline Fat Mass (\%) & $n=26$ & $37,96 \pm 5,49$ & $n=14$ & $37,75 \pm 5,80$ & $0,910^{c}$ \\
\hline Fat Mass (kg) & $n=26$ & $23,15 \pm 8,64$ & $n=14$ & $25,60 \pm 7,70$ & $0,307^{a}$ \\
\hline Fat Mass Index $\left(\mathrm{kg} / \mathrm{m}^{2}\right)$ & $\mathrm{n}=26$ & $10,38 \pm 2,87$ & $\mathrm{n}=14$ & $10,41 \pm 2,53$ & $0,973^{c}$ \\
\hline \multicolumn{6}{|l|}{ Fat Mass Index classes } \\
\hline Obesity & \multicolumn{2}{|c|}{$80,8 \%(21)$} & \multicolumn{2}{|c|}{$71,4 \%(10)$} & $0,317^{b}$ \\
\hline Pre-obesity & & & \multicolumn{2}{|c|}{$28,6 \%(4)$} & \\
\hline \multirow[t]{3}{*}{ Normal } & & & - & & \\
\hline & \multicolumn{2}{|c|}{$11,5 \%(3)$} & & & \\
\hline & \multicolumn{2}{|c|}{$7,7 \%(2)$} & & & \\
\hline Fat Free Mass (\%) & $\mathrm{n}=26$ & $29,69 \pm 4,14$ & $\mathrm{n}=12$ & $31,45 \pm 4,50$ & $0,233^{a}$ \\
\hline Fat Free Mass (kg) & $n=26$ & $17,65 \pm 4,62$ & $\mathrm{n}=12$ & $22,03 \pm 6,85$ & $0,026^{c}$ \\
\hline
\end{tabular}




\begin{tabular}{|c|c|c|c|c|c|}
\hline & \multicolumn{2}{|c|}{$\begin{array}{l}\text { Behavioral Group } \\
\mathrm{n}=35\end{array}$} & \multicolumn{2}{|c|}{$\begin{array}{l}\text { Standard Treatment Group } \\
\mathrm{n}=55\end{array}$} & p-value* \\
\hline Fat Free Mass Index $\left(\mathrm{kg} / \mathrm{m}^{2}\right)$ & $n=26$ & $7,93 \pm 1,13$ & $\mathrm{n}=12$ & $8,66 \pm 1,56$ & $0,128^{a}$ \\
\hline
\end{tabular}

\subsection{Follow-up intervention}

Table 2 shows that the mean BMI $z$-score decreased over time in both groups $(p<0,05)$. This decrease was more pronounced in the BG, probably because at 12 months of follow-up, the mean BMI z-score decreased by $22,3 \% \pm 18,7 \%$, while the STG decreased on average $7,9 \% \pm 14,6 \%(p<0,05)$. We also found that after 12 months, $31,4 \%$ and $20 \%$ of the children/adolescents of the BG and the STG, respectively, were no longer obese.

Moreover, the mean BMI z-score decreased more pronouncedly in the first 3 to 6 months in both groups (BG: $-0,41 ; p<0,05$ and STG: $-0,15 p<0,05$ ) than in the last 6 months (BG: $-0,12 p<0,05$ and STG: $-0,07 p>$ $0,05)$. However, only a significant difference was found between the groups in the decrease in BMI z-score between the beginning and after 3 or 6 months $(p<0,05)$.

Regarding the mean of fat mass index, it decreased in both groups, although the difference was only significant in the BG.

When analyzing the evolution of the mean fat free mass index, there was a decrease in both groups at 12 months of follow-up, and this decrease was lower in the BG $(0,1 \pm 0,7)$ than in the STG $(0,3 \pm 1,7)$ ( $p>$ $0,05)$.

The relationship between the evolution of the fat mass index and the evolution of the BMI z-score was also analyzed. We found a strong positive correlation between the decrease in the BMI z-score and the fat mass index at 12 months of follow-up $(r=0,8 ; p<0,05)$ in the BG.

Also, the analysis of the relationship between the mean fat free mass index and the mean BMI z-score, showed a positive correlation in both groups between baseline and after 12 months of follow-up (BG: $r=$ $0,7, p<0,05$; STG: $r=0,7, p=0,05$ ). 
Table 2

Nutritional evolution of children and adolescents.

\begin{tabular}{|c|c|c|c|c|c|c|c|c|}
\hline \multirow{2}{*}{ Variable } & & \multicolumn{2}{|l|}{ Baseline } & \multicolumn{2}{|c|}{$\begin{array}{l}\text { M2 } \\
\text { ( } 6 \text { months of } \\
\text { follow-up) }\end{array}$} & \multicolumn{2}{|c|}{$\begin{array}{l}\text { M3 } \\
\text { (12 months } \\
\text { follow-up) }\end{array}$} & \multirow[t]{3}{*}{$\begin{array}{l}\text { p- } \\
\text { value* }\end{array}$} \\
\hline & & $\begin{array}{l}\text { Mean } \pm \\
\text { SD }\end{array}$ & \multirow[t]{2}{*}{$\begin{array}{l}\text { Value } \\
\mathrm{p}\end{array}$} & $\begin{array}{l}\text { Mean } \pm \\
\text { SD }\end{array}$ & \multirow[t]{2}{*}{$\begin{array}{l}\text { Value } \\
\mathrm{p}\end{array}$} & $\begin{array}{l}\text { Mean } \pm \\
\text { SD }\end{array}$ & \multirow[t]{2}{*}{$\begin{array}{l}\text { Value } \\
\mathrm{p}\end{array}$} & \\
\hline & & $\%(n)$ & & $\%(n)$ & & $\%(n)$ & & \\
\hline \multirow[t]{2}{*}{ BMI z-score } & $\begin{array}{l}B G(n= \\
35)\end{array}$ & $\begin{array}{l}2,54 \pm \\
0,80\end{array}$ & \multirow[t]{2}{*}{$0,427^{a}$} & $\begin{array}{l}2,12 \pm \\
0,82\end{array}$ & \multirow[t]{2}{*}{$0,055^{b}$} & $\begin{array}{l}2,00 \pm \\
0,81\end{array}$ & \multirow[t]{2}{*}{$0,028^{b}$} & $0,000^{c}$ \\
\hline & $\begin{array}{l}\text { STG(n } \\
=55)\end{array}$ & $\begin{array}{l}2,57 \pm \\
0,56\end{array}$ & & $\begin{array}{l}2,43 \pm \\
0,49\end{array}$ & & $\begin{array}{l}2,36 \pm \\
0,59\end{array}$ & & $0,000^{d}$ \\
\hline \multicolumn{9}{|l|}{$\begin{array}{l}\text { BMI z-score } \\
\text { classes }\end{array}$} \\
\hline Obesity & \multirow[t]{3}{*}{$B G$} & $\begin{array}{l}80 \% \\
(28)\end{array}$ & \multirow[t]{6}{*}{$0,660^{e}$} & $\begin{array}{l}54,3 \% \\
(19)\end{array}$ & \multirow[t]{6}{*}{$0,003^{f}$} & $\begin{array}{l}48,6 \% \\
(17)\end{array}$ & \multirow[t]{6}{*}{$0,005^{f}$} & \multirow[t]{3}{*}{0,000} \\
\hline Pre-obesity & & $20 \%(7)$ & & $\begin{array}{l}31,4 \\
(11)\end{array}$ & & $\begin{array}{l}34,3 \% \\
(12)\end{array}$ & & \\
\hline Eutrophic & & - & & $\begin{array}{l}14,3 \% \\
(5)\end{array}$ & & $\begin{array}{l}17,1 \% \\
(6)\end{array}$ & & \\
\hline Obesity & \multirow[t]{3}{*}{ STG } & $\begin{array}{l}83,6 \% \\
(46)\end{array}$ & & $\begin{array}{l}78,2 \% \\
(43)\end{array}$ & & $\begin{array}{l}63,6 \% \\
(35)\end{array}$ & & \multirow[t]{3}{*}{0,264} \\
\hline Pre-obesity & & $\begin{array}{l}16,4 \% \\
(9)\end{array}$ & & $\begin{array}{l}21,8 \% \\
(12)\end{array}$ & & $\begin{array}{l}36,4 \% \\
(20)\end{array}$ & & \\
\hline Eutrophic & & - & & - & & - & & \\
\hline \multirow[t]{2}{*}{ Fat Mass (kg) } & $\begin{array}{l}B G(n= \\
24)\end{array}$ & $\begin{array}{l}24,03 \pm \\
8,39\end{array}$ & \multirow[t]{2}{*}{$0,850^{a}$} & \multirow{2}{*}{\multicolumn{2}{|c|}{ - }} & $\begin{array}{l}21,97 \pm \\
7,53\end{array}$ & \multirow[t]{2}{*}{$0,404^{b}$} & 0,037 \\
\hline & $\begin{array}{l}\text { STG(n } \\
=10)\end{array}$ & $\begin{array}{l}25,40 \pm \\
8,99\end{array}$ & & & & $\begin{array}{l}24,28 \pm \\
6,44\end{array}$ & & $0,029^{h}$ \\
\hline \multirow[t]{2}{*}{ Fat Mass (\%) } & $B G$ & $\begin{array}{l}38,45 \pm \\
5,27\end{array}$ & \multirow[t]{2}{*}{$0,557^{b}$} & \multirow{2}{*}{\multicolumn{2}{|c|}{ - }} & $\begin{array}{l}35,62 \pm \\
6,54\end{array}$ & \multirow[t]{2}{*}{$0,597^{b}$} & $0,209^{h}$ \\
\hline & STG & $\begin{array}{l}37,32 \pm \\
5,11\end{array}$ & & & & $\begin{array}{l}34,42 \pm \\
3,96\end{array}$ & & $0,596^{\mathrm{h}}$ \\
\hline Fat Mass Index & $B G$ & $\begin{array}{l}10,64 \pm \\
2,83\end{array}$ & $0,575^{b}$ & - & & $\begin{array}{l}9,35 \pm \\
2,66\end{array}$ & $0,712^{b}$ & $0,002^{b}$ \\
\hline $\begin{array}{l}\text { a Mann-Whitney } \\
\text { ANOVA test repe } \\
\text { simulation; }{ }^{9} \text { Wilc } \\
\text { deviation. }\end{array}$ & $\begin{array}{l}\text { t; }{ }^{b} \text { T-stu } \\
\text { d meas } \\
\text { on test; }\end{array}$ & $\begin{array}{l}\text { test ind } \\
; \text {; } \text { Friedn } \\
\text { tudent te }\end{array}$ & $\begin{array}{l}\text { ndente- } \\
\text { test; }{ }^{\mathrm{e}} \mathrm{C} \\
\text { paired- }\end{array}$ & $\begin{array}{l}\text { amples; }{ }^{\mathrm{b}} \mathrm{T} \\
\text { i-square t } \\
\text { amples); * }\end{array}$ & $\begin{array}{l}\text { tudent te } \\
\mathrm{st}^{\mathrm{f}}{ }^{\mathrm{C}} \mathrm{Chi} \text {-s } \\
\text { ifference }^{2}\end{array}$ & $\begin{array}{l}\text { t (indeper } \\
\text { dare test I } \\
\text { n each gr }\end{array}$ & $\begin{array}{l}\text { ent san } \\
\text { onte Ca } \\
\text { up; SD = }\end{array}$ & $\begin{array}{l}\text { e); }{ }^{c} \\
\text { andard }\end{array}$ \\
\hline
\end{tabular}




\begin{tabular}{|c|c|c|c|c|c|c|c|}
\hline & \multirow[b]{3}{*}{ STG } & \multirow{2}{*}{\multicolumn{2}{|c|}{ Baseline }} & \multirow{3}{*}{$\begin{array}{l}\text { M2 } \\
\text { (6 months of } \\
\text { follow-up) }\end{array}$} & \multirow{2}{*}{\multicolumn{2}{|c|}{$\begin{array}{l}\text { M3 } \\
\text { (12 months } \\
\text { follow-up) }\end{array}$}} & \multirow{2}{*}{$\begin{array}{l}\text { p- } \\
\text { value* }\end{array}$} \\
\hline & & & & & & & \\
\hline & & \multicolumn{2}{|l|}{$\begin{array}{l}10,05 \pm \\
2,61\end{array}$} & & \multicolumn{2}{|l|}{$\begin{array}{l}9,69 \pm \\
1,89\end{array}$} & $0,707^{b}$ \\
\hline \multicolumn{8}{|l|}{$\begin{array}{l}\text { Fat Mass Index } \\
\text { classes }\end{array}$} \\
\hline Obesity & \multirow[t]{3}{*}{$B G$} & $\begin{array}{l}83,3 \% \\
(20)\end{array}$ & \multirow[t]{6}{*}{$0,220^{f}$} & \multirow[t]{6}{*}{-} & $\begin{array}{l}66,7 \% \\
(16)\end{array}$ & \multirow[t]{6}{*}{$0,775^{f}$} & $0,000^{g}$ \\
\hline $\begin{array}{l}\text { Fat Mass Index } \\
\text { excess }\end{array}$ & & $\begin{array}{l}12,5 \% \\
(3)\end{array}$ & & & $\begin{array}{l}29,2 \% \\
(7)\end{array}$ & & \\
\hline Normal & & $4,2 \%(1)$ & & & $4,2 \%(1)$ & & \\
\hline Obesity & \multirow[t]{3}{*}{ STG } & $60 \%(6)$ & & & $80 \%(8)$ & & $0,004^{g}$ \\
\hline $\begin{array}{l}\text { Fat Mass Index } \\
\text { excess }\end{array}$ & & $40 \%(4)$ & & & $20 \%(2)$ & & \\
\hline Normal & & - & & & - & & \\
\hline \multirow[t]{2}{*}{$\begin{array}{l}\text { Fat Free Mass } \\
(\mathrm{kg})\end{array}$} & $\begin{array}{l}\text { BG }(n= \\
23)\end{array}$ & $\begin{array}{l}18,30 \pm \\
4,30\end{array}$ & \multirow[t]{2}{*}{$0,064^{a}$} & \multirow[t]{2}{*}{ - } & $\begin{array}{l}18,91 \pm \\
4,15\end{array}$ & \multirow[t]{2}{*}{$0,042^{\mathrm{a}}$} & $0,140^{g}$ \\
\hline & $\begin{array}{l}\text { STG }(n \\
=8)\end{array}$ & $\begin{array}{l}21,96 \pm \\
5,16\end{array}$ & & & $\begin{array}{l}22,18 \pm \\
4,03\end{array}$ & & $0,892^{h}$ \\
\hline \multirow[t]{2}{*}{$\begin{array}{l}\text { Fat Free Mass } \\
(\%)\end{array}$} & $B G$ & $\begin{array}{l}29,77 \pm \\
4,19\end{array}$ & \multirow[t]{2}{*}{$0,047^{a}$} & \multirow[t]{2}{*}{ - } & $\begin{array}{l}31,07 \pm \\
4,39\end{array}$ & \multirow[t]{2}{*}{$0,527^{\mathrm{a}}$} & $0,015^{g}$ \\
\hline & STG & $\begin{array}{l}31,76 \pm \\
3,16\end{array}$ & & & $\begin{array}{l}30,98 \pm \\
3,70\end{array}$ & & $0,559^{h}$ \\
\hline \multirow[t]{2}{*}{$\begin{array}{l}\text { Fat Free Mass } \\
\text { Index }\end{array}$} & $B G$ & $\begin{array}{l}8,04 \pm \\
1,11\end{array}$ & \multirow[t]{2}{*}{$0,240^{\mathrm{a}}$} & \multirow[t]{2}{*}{-} & $\begin{array}{l}7,94 \pm \\
1,09\end{array}$ & \multirow[t]{2}{*}{$0,294^{b}$} & $0,484^{g}$ \\
\hline & STG & $\begin{array}{l}8,49 \pm \\
1,29\end{array}$ & & & $\begin{array}{l}8,18 \pm \\
1,04\end{array}$ & & $0,612^{b}$ \\
\hline \multicolumn{8}{|c|}{$\begin{array}{l}\text { a Mann-Whitney test; }{ }^{\mathrm{b}} \text { T-studen test independente-samples; }{ }^{\mathrm{b}} \text { T-student test (independent sample); }{ }^{\mathrm{c}} \\
\text { ANOVA test repeated measures; }{ }^{\mathrm{d}} \text { Friedman test; }{ }^{\mathrm{e}} \text { Chi-square test; }{ }^{\mathrm{f}} \text { Chi-square test Monte Carlo } \\
\text { simulation; }{ }^{g} \text { Wilcoxon test; }{ }^{\mathrm{h}} \mathrm{T} \text {-student test (paired-samples); }{ }^{*} \text { Difference in each group; SD = standard } \\
\text { deviation. }\end{array}$} \\
\hline
\end{tabular}

\section{Discussion}

The prevention of childhood obesity is undoubtedly the best treatment, but when obesity is already installed, an organized intervention should be instituted for the correct dietary counseling, in order to maintain or lose weight in children [18]. The literature has pointed out that the treatment of childhood 
overweight should include a therapy based on the modification of behaviors with the involvement of children/adolescent and the participation of tutors in the treatment process [19]. However, there is no evidence regarding the most effective type of behavioral approach [20]. The present study contributed to the evidence of a behavioral and personalized intervention to the children reality, through the use of a behavioral contract in the treatment of childhood overweight. The use of reinforcement or reward systems of the desired behavior is useful since it encourages new health related behaviors [21]. Finkelstein et al. [22], compared two groups of adults with pre-obesity or obesity in a weight loss program. One of the groups received a reward if the goals of weight loss were achieved and the other group received no reward. They found that the adults who received a reward lost on average twice as much weight as those who did not receive a reward after the four months of intervention $(3,4 \mathrm{~kg} v \mathrm{~s} 1,4 \mathrm{~kg}, \mathrm{p}<0,05)$. Another study looked at the effect of using the rewarded and unrewarded behavioral contract on weight loss with three groups of five female children from five to ten years old. The authors concluded that children in the rewarded group lost more weight than children in the unrewarded group after 12 weeks of follow-up [23]. Likewise, in the present study, the children and adolescents of the BG received a reward when the goals were fulfilled, and at the end of the intervention they decreased the BMI z-score more than in the STG.

In a randomized study [24], the authors evaluated the effects of a six-month intervention for the treatment of obesity in children aged five to eight years old. The children of the intervention group received monthly sessions on eating and physical activity behavior change, also signing a behavioral change contract. Children in the control group participated in a standard treatment with regular visits to their physician in order to follow their advice. However, unlike the results of the present study, these authors did not obtain significant differences in the BMI z-score after six months of follow-up.

Although reference values for body composition for pediatric age have already been published [16], there are few studies that include body composition as an outcome of nutritional intervention in this population. In the present study, there was a significant improvement in body composition at 12 months of follow-up in the BG, particularly in the fat mass index. In a randomized study with obese children aged seven to nine years old which aimed to compare the impact of a program of 14 group sessions with a program of two routine counselling consultations in body composition and metabolic profile, the authors found higher decreases of fat mass $(\mathrm{kg})$ in the group program children, with a decrease of BMI z-score greater than or equal to 0,25 [25]. These results corroborate those obtained in the present study, where there was a greater decrease in fat mass $(\mathrm{kg})$ after 12 months follow-up in the BG than in the STG. However, other authors suggest that a decrease of $0,5 \mathrm{BMI} z$-score up to six months or 0,6 between six and twelve months is associated with a clinically relevant reduction in the percentage of fat mass [26].

The present study also had some limitations that should be considered. As a limiting factor, the reduced sample size and retrospective design are included. In addition, during the initial characterization of the sample, there was a significant difference in BMI between the two groups. This result may also be due to a statistically significant difference between the groups regarding weight and height. However, when the BMI z-score was evaluated, no significant difference was found. Also, the fact that the practice of physical activity or time spent on sedentary activities has not been evaluated can be considered a

Page $10 / 16$ 
confounding factor. The short follow-up may limit the conclusions regarding the long-term effects of the intervention. However, this is a limitation of many of the intervention studies in the treatment of obesity.

As strengths to the present work, we compared the intervention with a standard treatment for pediatric excess weight. Furthermore, it also added evidence regarding the use of the behavioral contract method in the treatment of overweight children.

It is noteworthy, however, to consider the importance of future studies in this area with a more rigorous methodology, in order to demonstrate the potential advantages of this type of intervention in the treatment of pediatric overweight. Future studies should aim to be prospective, include a larger number of participants, analyze the social condition and the pubertal stage; evaluate the practice of physical activity and evaluate the results with a follow-up time which is longer than 12 months.

We conclude the superior outcomes presented by the BG versus STG are due to the follow-up protocol that was based on the use behavioral contract with reward, a greater proximity and temporal adjustment between nutrition consultations and greater accountability and commitment of the children / adolescent to treatment.

In summary, the use of an intervention through a behavioral contract in children and adolescents affected by overweight has shown to be effective in decreasing BMI z-score at six and twelve months of follow-up. However, the outcomes of the behavioral approach appear to have a higher impact with a 12-month intervention when compared with a standard dietary counseling intervention.

\section{List Of Abbreviations}

BG - Behavioral Group

BMI - Body Mass Index

STG - Standard Treatment Group

SD - Standard Deviation

Kg - Kilogram

\section{Declarations}

\subsection{Ethics approval and consent to participate}

All ethical requirements were ensured, and the study was analyzed and approved by the Ethics Committee of the Faculty of Medicine of the University of Lisbon and the North Lisbon University Hospital Center (reference of approval code: 459/18). The informed consent was also approved by the tutors. 


\subsection{Consent for publication}

Not applicable.

\subsection{Availability of data and materials}

All data generated or analysed during this study are included in this published article.

\subsection{Competing interests}

The authors declare no competing interests.

\subsection{Funding}

This research received no external funding.

\subsection{Authors' contributions}

Conceptualization, I.A., J.S. and V.C.; methodology, I.A., J.S. and V.C.; investigation, I.A and V.C.; writingoriginal draft preparation, V.C.; writing-review and editing, I.A and J.S.. All authors have read and agreed to the published version of the manuscript.

\subsection{Acknowledgements}

We would like to thank the collaborators of the Dietetic and Nutrition Service of the Lisbon North Hospital Center and all the tutors of the children and adolescents who agreed to participate in this work during data collection.

\section{References}

1. Farpour-Lambert NJ, Baker JL, Hassapidou M, Holm JC, Nowicka P, O"malley G, et al. Childhood Obesity Is a Chronic Disease Demanding Specific Health Care - A Position Statement from the Childhood Obesity Task Force (COTF) of the European Association for the Study of Obesity (EASO). Obes Facts. 2015;8(5):342-9.

2. Umer A, Kelley GA, Cottrell LE, Giacobbi P, Innes KE, Lilly CL. Childhood obesity and adult cardiovascular disease risk factors: a systematic review with meta-analysis. BMC Public Health [Internet]. 2017 Dec 29;17(1):683. Available from: http://bmcpublichealth.biomedcentral.com/articles/10.1186/s12889-017-4691-z 
3. Marques T, Moniz M, Cabral M, Nizarali Z, Coelho R, Monteiro AC, et al. Artigo original Obesidade infantil - caraterização de uma população com seguimento hospitalar. Acta Pediatr Port. 2008;2:295-300.

4. Mollerup PM, Gamborg M, Trier C, Bøjsøe C, Nielsen TRH, Baker JL, et al. A hospital-based child and adolescent overweight and obesity treatment protocol transferred into a community healthcare setting. Taheri S, editor. PLoS One [Internet]. 2017 Mar 6;12(3):e0173033. Available from: http://dx.plos.org/10.1371/journal.pone.0173033

5. Walsh SM, Palmer W, Welsh JA, Vos MB. Challenges and Successes of a Multidisciplinary Pediatric Obesity Treatment Program. Nutr Clin Pract [Internet]. 2014 Dec 21;29(6):780-5. Available from: http://doi.wiley.com/10.1177/0884533614551839

6. Bosch-Capblanch X, Abba K, Prictor M, Garner P. Contracts between patients and healthcare practitioners for improving patients' adherence to treatment, prevention and health promotion activities. Cochrane Database Syst Rev [Internet]. 2007 Apr 18;(2). Available from: http://doi.wiley.com/10.1002/14651858.CD004808.pub3

7. Ziser K, Resmark G, Giel KE, Becker S, Stuber F, Zipfel S, et al. The effectiveness of contingency management in the treatment of patients with anorexia nervosa: A systematic review. Eur Eat Disord Rev [Internet]. 2018 Sep;26(5):379-93. Available from: http://doi.wiley.com/10.1002/erv.2590

8. Schlenk EA, Boehm S. Behaviors in type II diabetes during contingency contracting. Appl Nurs Res [Internet]. 1998 May;11(2):77-83. Available from: http://linkinghub.elsevier.com/retrieve/pii/S0897189798802188

9. Hartz GW, Brennan PL, Aulakh JS, Estrin MT. Behavioral Contracting with Psychiatric Residents in Long-Term Care: An Exploratory Study. Clin Gerontol [Internet]. 2010 Aug 31;33(4):347-62. Available from: http://www.tandfonline.com/doi/abs/10.1080/07317115.2010.502466

10. Lesser LI, Thompson CA, Luft HS. Association Between Monetary Deposits and Weight Loss in Online Commitment Contracts. Am J Heal Promot [Internet]. 2018 Jan 8;32(1):198-204. Available from: http://journals.sagepub.com/doi/10.1177/0890117116661157

11. Sykes-Muskett BJ, Prestwich A, Lawton RJ, Armitage CJ. The effect of pair-based monetary contingency contracts for weight loss: Results from a randomized controlled pilot study. Obesity [Internet]. 2017 Mar;25(3):506-9. Available from: http://doi.wiley.com/10.1002/oby.21758

12. Kullgren JT, Troxel AB, Loewenstein G, Asch DA, Norton LA, Wesby L, et al. Individual- Versus GroupBased Financial Incentives for Weight Loss. Ann Intern Med [Internet]. 2013 Apr 2;158(7):505. Available from: http://annals.org/article.aspx?doi=10.7326/0003-4819-158-7-201304020-00002

13. Oude Luttikhuis H, Baur L, Jansen H, Shrewsbury VA, O’Malley C, Stolk RP, et al. Interventions for treating obesity in children. Cochrane Database Syst Rev [Internet]. 2009 Jan 20;(1). Available from: http://cochranelibrary-wiley.com/store/10.1002/14651858.CD001872.pub2/asset/CD001872.pdf? $v=1 \& \mathrm{t}=\mathrm{jez} \ln 1 \mathrm{nl} \& \mathrm{~s}=\mathrm{e} 7 \mathrm{e} 09 \mathrm{~d} 3 \mathrm{c} 334084819 \mathrm{e} 88320043489 \mathrm{ec} 61 \mathrm{~d} 5 \mathrm{~d} 8 \mathrm{e} 43$

14. Mameli C, Krakauer JC, Krakauer NY, Bosetti A, Ferrari CM, Schneider L, et al. Effects of a multidisciplinary weight loss intervention in overweight and obese children and adolescents: 11 years 
of experience. Meyre D, editor. PLoS One [Internet]. 2017 Jul 13 [cited 2019 Jan 23];12(7):e0181095. Available from: https://dx.plos.org/10.1371/journal.pone.0181095

15. World Health Organization. Growth reference 5-19 years [Internet]. [cited 2018 Sep 12]. Available from: http://www.who.int/growthref/who2007_bmi_for_age/en/

16. Wells JC, Williams JE, Chomtho S, Darch T, Grijalva-Eternod C, Kennedy K, et al. Body-composition reference data for simple and reference techniques and a 4-component model: a new UK reference child. Am J Clin Nutr [Internet]. 2012 Dec 1;96(6):1316-26. Available from: https://academic.oup.com/ajcn/article/96/6/1316/4571457

17. Vanltallie TB, Yang MU, Heymsfield SB, Funk RC, Boileau RA. Height-normalized indices of the body's fat-free mass and fat mass: potentially useful indicators of nutritional status. Am J Clin Nutr [Internet]. 1990 Dec 1;52(6):953-9. Available from: https://academic.oup.com/ajcn/article/52/6/953/4651256

18. Silva F, Ferreira E, Gonçalves R, Cavaco A. Obesidade Pediátrica: A Realidade de Uma Consulta. [Pediatric obesity: the reality of one consultation]. Acta Med Port [Internet]. 2012;25(2):91-6. Available from: http://pesquisa.bvsalud.org/portal/resource/pt/mdl-22985919

19. Hoelscher DM, Kirk S, Ritchie L, Cunningham-Sabo L. Position of the Academy of Nutrition and Dietetics: Interventions for the Prevention and Treatment of Pediatric Overweight and Obesity. J Acad Nutr Diet [Internet]. 2013 Oct;113(10):1375-94. Available from:

http://dx.doi.org/10.1016/j.jand.2013.08.004

20. Dolinsky DH, Armstrong SC, Kinra S. The Clinical Treatment of Childhood Obesity. Indian J Pediatr [Internet]. 2013 Mar 7;80(S1):48-54. Available from: http://link.springer.com/10.1007/s12098-0120766-0

21. Reinehr T. Effectiveness of lifestyle intervention in overweight children. Proc Nutr Soc [Internet]. 2011 Nov 1;70(04):494-505. Available from: http://www.journals.cambridge.org/abstract_S0029665111000577

22. Finkelstein EA, Tham K-W, Haaland BA, Sahasranaman A. Applying economic incentives to increase effectiveness of an outpatient weight loss program (TRIO) - A randomized controlled trial. Soc Sci Med [Internet]. 2017 Jul;185:63-70. Available from: http://dx.doi.org/10.1016/j.socscimed.2017.05.030

23. Aragona J, Cassady J, Drabman RS. Treating overweight children through parental training and contingency contracting. J Appl Behav Anal [Internet]. 1975;8(3):1311852. Available from: http://www.pubmedcentral.gov/articlerender.fcgi?artid=1311852

24. O'Connor TM, Hilmers A, Watson K, Baranowski T, Giardino AP. Feasibility of an obesity intervention for paediatric primary care targeting parenting and children: Helping HAND. Child Care Health Dev [Internet]. 2013 Jan;39(1):141-9. Available from: http://doi.wiley.com/10.1111/j.13652214.2011.01344.x

25. Kalavainen M, Utriainen P, Vanninen E, Korppi M, Nuutinen O. Impact of childhood obesity treatment on body composition and metabolic profile. World J Pediatr [Internet]. 2012 Feb 21 [cited 2019 Jan 
19];8(1):31-7. Available from: http://link.springer.com/10.1007/s12519-011-0324-2

26. Hunt LP, Ford A, Sabin MA, Crowne EC, Shield JPH. Clinical measures of adiposity and percentage fat loss: which measure most accurately reflects fat loss and what should we aim for? Arch Dis Child [Internet]. 2007 May 1;92(5):399-403. Available from:

http://adc.bmj.com/cgi/doi/10.1136/adc.2006.103986

Figures

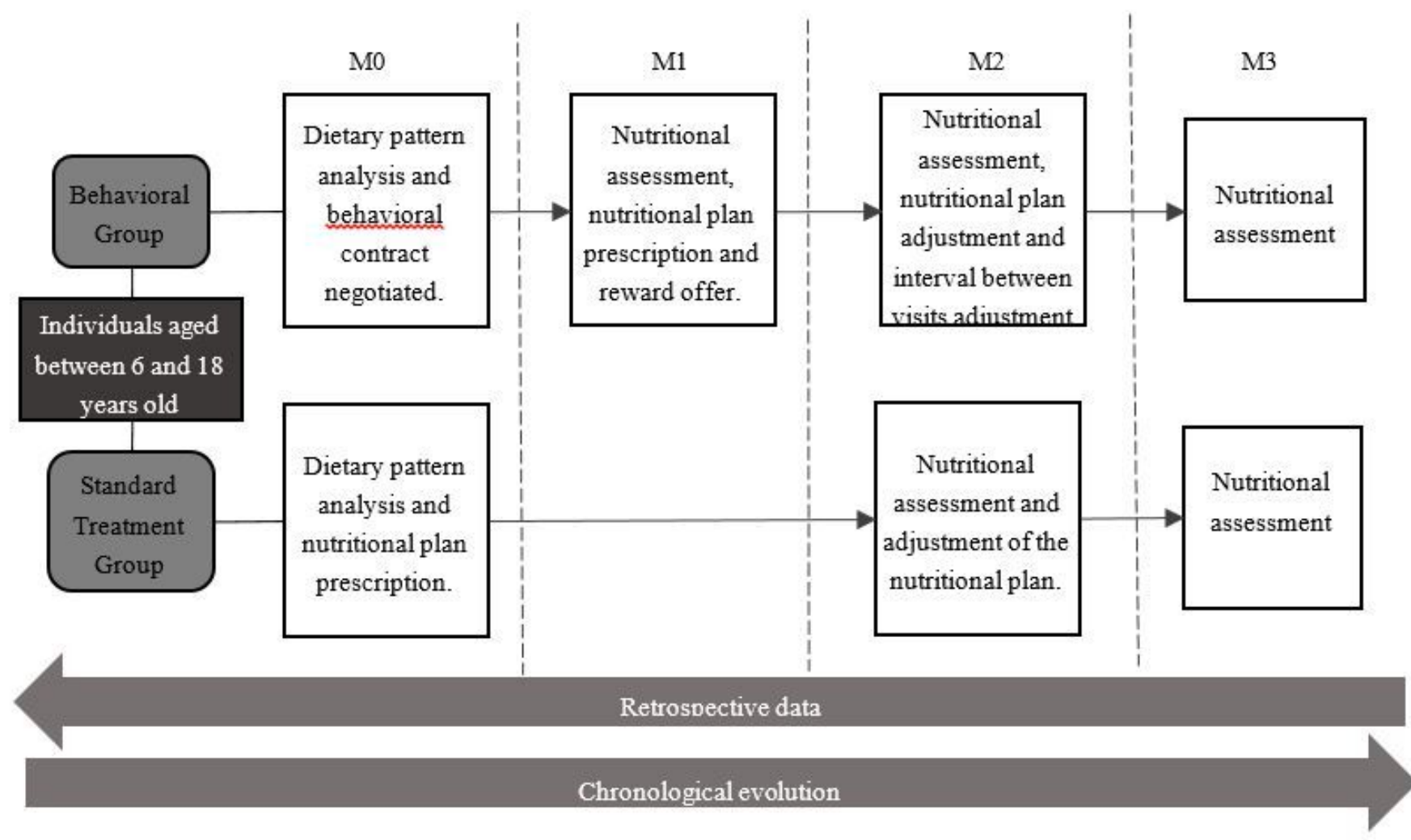

Figure 1

Flowchart of the data collection methodology. 


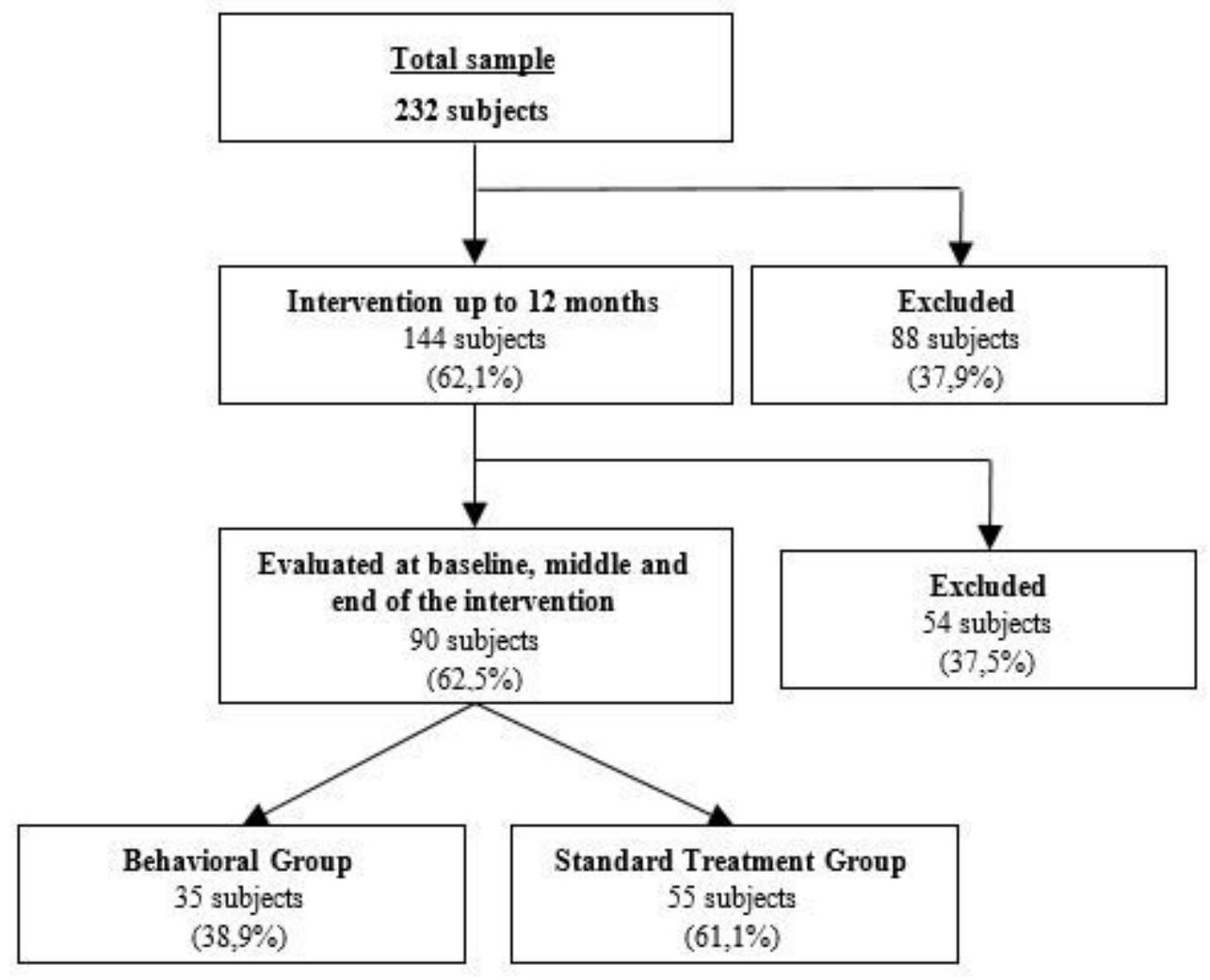

Figure 2

Sample selection. 